\title{
Erratum to key topics in pulmonary vascular diseases (assembly 13) from the European Respiratory Society 2018 Parisian Congress
}

doi: $10.21037 /$ jtd.2018.10.127

View this article at: http://dx.doi.org/10.21037/jtd.2018.10.127

Erratum to: J Thorac Dis 2018;10:S3029-33

Key topics in pulmonary vascular diseases (assembly 13) from the European Respiratory Society 2018 Parisian Congress

In the article that appeared on Page 3029-3033, Vol 10, Suppl 25 (September 2018) Issue of the Fournal of Thoracic Disease (7TD) (1), Dr. Vonk Noordegraaf's surname was incorrectly cited as Noordegraaf. The correct citation should be: Ramjug S, Vonk Noordegraaf A, Delcroix M. Key topics in pulmonary vascular diseases (assembly 13) from the European Respiratory Society 2018 Parisian Congress. J Thorac Dis 2018;10(Suppl 25):S3029-S3033. doi: 10.21037/jtd.2018.09.07.

The publisher regrets the error.

\section{References}

1. Ramjug S, Noordegraaf AV, Delcroix M. Key topics in pulmonary vascular diseases (assembly 13) from the European Respiratory Society 2018 Parisian Congress. J Thorac Dis 2018;10:S3029-33.

Cite this article as: Erratum to key topics in pulmonary vascular diseases (assembly 13) from the European Respiratory Society 2018 Parisian Congress. J Thorac Dis 2018;10(11):E792. doi: 10.21037/jtd.2018.10.127 